\title{
Association between ondansetron use and symptom persistence in children with concussions: A 5P substudy
}

\author{
Jocelyn Gravel, MD, MSc*; Kathy Boutis, $\mathrm{MD}^{\dagger}$; Ken Tang, $\mathrm{PhD}^{\ddagger}$; Miriam H. Beauchamp, $\mathrm{PhD}^{\text {ॠ; }}$ \\ Stephen B. Freedman, MD**; Alexander Sasha Dubrovsky, $\mathrm{MD}^{+\dagger}$; Isabelle Gagnon, $\mathrm{PhD}^{\ddagger \neq}$; \\ Frank Momoli, $\mathrm{PhD}^{\ddagger \S \S \pi T ; ~ R o g e r ~ Z e m e k, ~} \mathrm{MD}^{\S}$ on behalf of the Pediatric Emergency Research Canada \\ (PERC) 5P study group
}

\section{CLINICIAN'S CAPSULE}

What is known about the topic?

Most children who sustain a concussion suffer from postconcussion symptoms for many weeks following the accident.

What did this study ask?

Is there an association between ondansetron administration and the presence of persistent post-concussion symptoms at 1 week and 1 month in children?

What did this study find?

This observational study found that the use of ondansetron among children presenting to the emergency department with an acute concussion was associated with a higher risk of persistent symptoms at 1 month.

Why does this study matter to clinicians?

The treatment of short-term symptoms of a concussion should be balanced with the potential long-term harm of ondansetron.

\section{ABSTRACT}

Objective: Ondansetron is increasingly administered to children suffering from concussion-associated nausea/vomiting. We examined the association between ondansetron administration and post-concussion symptoms in children at 1 week and 1 month following the concussion.

Methods: This was a secondary analysis of data collected prospectively in a cohort study conducted in nine pediatric emergency departments (EDs) (5P study). Participants were children ages between 5 and 17.99 years who sustained a concussion in the previous 48 hours. For the current study, only $5 \mathrm{P}$ participants who reported nausea and/or vomiting in the ED were eligible. The exposure of interest was ondansetron administration; the comparison group included all other participants. The primary outcome was an increase in at least three symptoms of the Post-Concussion Symptom Inventory score at 1 week and 1 month following trauma.

Results: Among the 3,063 children included in the 5P study, $1805(59 \%)$ reported nausea and provided data at 1 week and/ or 1 month. Among them, 132 (7\%) received ondansetron. Multivariable logistic regression adjusted for confounders did not show an association between ondansetron use and the risk of persistent post-concussion symptoms at 1 week (OR: 1.13 [95\% Cl: 0.86-1.49]), but it was associated with a higher risk at 1 month (OR: 1.33 [95\% Cl: 1.05-1.97]).

Conclusion: In children presenting to the ED with an acute concussion, ondansetron use was associated with a higher risk of persistent post-concussion symptoms at 1 month. Although this may be related to the limitations of the design, it highlights the importance of evaluating this association using a randomized clinical trial.

\section{RÉSUMÉ}

Objectif: On administre de plus en plus souvent de l'ondansétron aux enfants qui souffrent de nausées ou de vomissements associés à une commotion cérébrale. L'étude visait à examiner l'association entre l'utilisation de l'ondansétron et les symptômes liés à une commotion cérébrale chez les enfants, une semaine et un mois suivant le trauma.

From the *Department of Pediatrics, CHU Sainte-Justine, Université de Montréal, Montréal, QC; †Department of Pediatrics, The Hospital for Sick Children, University of Toronto, Toronto, ON; ¥Clinical Research Unit, Children's Hospital of Eastern Ontario Research Institute, Ottawa, ON; §Department of Pediatrics, Children's Hospital of Eastern Ontario Research Institute, Ottawa, ON; IDepartment of Psychology, Université de Montréal, Montréal, QC; **Department of Pediatrics, Alberta's Children Hospital, Calgary, AB; ††Department of Pediatrics, Montreal Children's Hospital, McGill University Health Centre, Montréal, QC; $¥ ¥$ Research Institute of the McGill University Health Centre, Montréal, QC; §§School of Epidemiology, Public Health and Preventive Medicine, University of Ottawa, Ottawa, ON; and the IT|Ottawa Hospital Research Institute, Ottawa, ON.

Correspondence to: Dr. Jocelyn Gravel, Department of Pediatrics, CHU Sainte-Justine, 3175 Chemin Côte Sainte-Catherine, Montréal, QC H3T 1C5, Canada; Email: graveljocelyn@hotmail.com 
Méthode: II s'agit d'une analyse secondaire de données recueillies dans le cadre d'une étude prospective de cohorte (étude 5P), menée dans 9 services des urgences (SU) pédiatriques. Les participants étaient des enfants âgés de 5 à 17,99 ans, qui avaient subi une commotion cérébrale au cours des 48 heures précédentes. Seulement les participants de l'étude 5P faisant état de nausées ou de vomissements au SU, étaient admissibles à l'étude en question. Le point d'intérêt était l'administration d'ondansétron; le groupe de comparaison était formé de tous les autres participants. Le principal critère d'évaluation consistait en l'intensification d'au moins 3 symptômes selon l'inventaire des symptômes postcommotionnels, une semaine et un mois suivant le trauma.

Résultats: Sur les 3063 enfants ayant participé à l'étude 5P, 1805 (59\%) avaient fait état de nausées ou de vomissements, et avaient fourni des données au bout d'une semaine et d'un mois. Parmi ceux-ci, 132 enfants (7\%) avaient reçu de I'ondansétron. $D^{\prime}$ après une analyse de régression logistique à plusieurs variables, rajustée pour tenir compte de facteurs parasites, il n'y avait pas d'association entre I'utilisation de I'ondansétron et le risque de persistance de symptômes postcommotionnels au bout d'une semaine (risque relatif approché [RRA] : 1,13 [IC à $95 \%: 0,86-1,49]$ ), mais une association a été établie avec une augmentation du risque au bout d'un mois (RRA : 1,33 [IC à $95 \%$ : 1,05-1,97]).

Conclusions: D'après les résultats de l'étude, I'utilisation de I'ondansétron chez les enfants traités au SU pour une commotion cérébrale en phase aiguë a été associée à une augmentation du risque de persistance de symptômes postcommotionnels au bout d'un mois. Si les constatations peuvent être liées aux limites du plan d'étude, elles font néanmoins ressortir l'importance d'évaluer la relation dans le cadre d'un essai clinique à répartition aléatoire.

Keywords: concussion, children, ondansetron

\section{INTRODUCTION}

A concussion is a problem commonly evaluated in the emergency department (ED). Recent studies suggest that children may represent as much as $90 \%$ of all concussions $^{1}$ with an annual incidence for teenagers, varying between $10.5 / 1,000$ to $16.5 / 1,000 .^{2}$ Between $55 \%$ and $90 \%$ of patients who sustain a concussion suffer from post-concussion symptoms at 1 week following the accident. ${ }^{3-5}$ These symptoms can be cognitive (memory loss, attention deficit, etc.), somatic (headache, fatigue, nausea), or psychological (depression, irritability, etc.) in nature. Moreover, studies report that $40 \%$ of concussed patients suffer persistent symptoms at 1 month, ${ }^{6}$ and as many as $15 \%$ remain symptomatic at 1 year post-injury. ${ }^{7,8}$

Many patients requiring medical attention following a concussion are initially evaluated in the ED. ${ }^{9}$ As soon as proper assessment is completed, treatments offered for patients suffering from a concussion are limited and mainly directed at alleviating symptoms. This includes medication given in the acute phase to decrease pain, nausea, or sometimes dehydration secondary to vomiting. Aside from guidelines recommending a period of activity restriction (physical and cognitive rest), ${ }^{10-14}$ there is little evidence to inform management of the concussion. Four systematic reviews confirm the paucity of studies evaluating treatment for a concussion, ${ }^{15-18}$ concluding that no acute intervention has been shown to improve the recovery and outcome of concussed patients.
Over the past few years, there is a growing trend among pediatric emergency physicians to prescribe ondansetron for children with a concussion who present with vomiting. ${ }^{19,20}$ Although being given mainly to relieve symptoms in the acute setting, ondansetron may improve recovery from a concussion by decreasing early symptoms of nausea and vomiting, decreasing energy demands, and enhancing brain rest. However, the clinical impact of ondansetron on time to recovery following a concussion has been poorly evaluated. The primary objective of this study was to evaluate the association between ondansetron administration and the presence of persistent postconcussive symptoms (PPCS) at 1 week and 1 month in children.

\section{METHODS}

\section{Design}

This was a secondary analysis of the data of the $5 \mathrm{P}$ study, ${ }^{5}$ a prospective cohort study of children with a concussion evaluated in multiple pediatric EDs in Canada. The idea of this sub-analysis emerged during the recruitment of patients but before the analysis.

\section{Setting}

Nine Canadian pediatric hospital EDs were involved in the project and recruited patients in 2013-2015. 
These sites are members of the Pediatric Emergency Research Canada (PERC) group. All of their institutional review boards approved the study.

\section{Participants}

Study participants were children and adolescents ages 5 to 17.99 years who presented in the first 48 hours following a head trauma and met the Zurich concussion criteria. ${ }^{10}$ Patients with a language barrier, abnormal neuroradiological findings, neurosurgical operative intervention, intubation or pediatric intensive care unit (PICU) care required, multisystem injuries with treatment requiring admission to the hospital, operating room or procedural sedation, neurological developmental delay, or intoxication were excluded. All participants/families provided written informed consent to be included in the study.

Participants of the sub-study reported nausea and/or vomiting at recruitment (based on an item from the self-reported version of the Post-Concussion Symptom Inventory [PCSI]).

\section{Outcomes}

The primary outcome was PPCS at 1 week following the index traumatic event, as defined in the 5P study. ${ }^{5}$ This was defined as an increase from the preconcussion baseline of at least three symptoms from the PCSI. The PCSI is a symptom scale that queries symptoms reflecting physical, cognitive, emotional, and sleep domains. ${ }^{21}$ The decision to evaluate the outcome at 1 week was based on the observation that more than $50 \%$ of children who sustain a concussion suffer from persistent symptoms at 1 week, ${ }^{18,22,23}$ and that most guidelines recommend rest for at least 1 week. $^{12,14}$ Because the outcome may be more important at 1 month for some individuals, persistence of symptoms for 1 month was also included as a primary outcome.

Secondary outcomes included the presence of nausea at 1 week and 1 month.

\section{Treatment}

The exposure of interest was a dichotomous variable representing those who received at least a single dose of intravenous or oral ondansetron in the ED. The comparison (reference) group included all other children with nausea and/or vomiting at baseline but did not receive ondansetron.

\section{Demographic and clinical characteristics}

Because this was not a randomized trial, other characteristics were considered as covariates in the analyses to minimize the risk of confounding bias when estimating the treatment effect of ondansetron. We considered a broad range of 37 pre-treatment variables measured in the original $5 \mathrm{P}$ study as the initial list of candidate confounders, which included demographic characteristics (e.g., age, sex), pre-morbid history (e.g., patient previous history of concussion, migraines, learning disability, depression), initial clinical presentation at the ED (e.g., loss of consciousness, mechanism of injury), extent of a wide range of acute concussion-related symptoms, as well as performance on standardized tests in the ED (e.g., Balance Error Scoring System tandem stance test). The full list of candidate confounders is presented in Table 1.

\section{Analysis}

Univariate and multivariable logistic regression analyses were used to estimate the relationship between treatment (receiving or not receiving ondansetron in the ED) and each of the four study outcomes. For each multivariable model, we maximized the number of covariates that were included based on a 15:1 event-per-variable ratio where "events" referred to the number of observations in the outcome level with the smaller proportion of the sample. Because the number of events differed for each of four study outcomes, the number of covariates ultimately included in the respective regression models also varied (see Table A1 in the Online Appendix). To prioritize the inclusion of the maximum number of covariates for regression adjustment, the non-linearity of continuous variables was not considered, and variables with greater than two categories were collapsed into two levels considered the most meaningful or treated as a continuous variable.

Because there was a non-trivial amount of missing values for covariates and outcomes $(24.2 \%$ of cases had at least one missing value), we initially performed multiple imputation using additive regression, bootstrap, and the predictive mean matching method. ${ }^{24}$ Variables in the imputation model included all 38 candidate covariates, the four study outcomes, plus the study site. The imputation procedure was repeated 25 times (i.e., $100 \mathrm{x}$ the fraction of cases with incomplete covariates). As soon as these imputed data sets were generated, the proposed multivariable logistic 


\begin{tabular}{|c|c|c|c|c|c|}
\hline \multirow[b]{2}{*}{ Variable } & \multirow[b]{2}{*}{ Scale range or category } & \multicolumn{2}{|c|}{ Ondansetron $\mathrm{N}=132$} & \multicolumn{2}{|c|}{ No ondansetron $\mathrm{N}=1,673$} \\
\hline & & N useable & $\begin{array}{l}\text { Mean (SD) or } \\
\text { frequency (\%) }\end{array}$ & N useable & $\begin{array}{l}\text { Mean (SD) or } \\
\text { frequency (\%) }\end{array}$ \\
\hline Age & 0-17.99 & 132 & $10.8(3.4)$ & 1,673 & $12.2(3.3)$ \\
\hline Sex & Female & 132 & 56 (42.4) & 1,673 & $715(42.7)$ \\
\hline Number of previous concussions & $0-6(6$ includes $6+)$ & 132 & $0.3(0.7)$ & 1,665 & $0.4(0.8)$ \\
\hline \multirow{5}{*}{ Prior concussion symptom duration } & $<1$ week & 132 & $117(88.6)$ & 1,663 & 1419 (85.3) \\
\hline & $1-2$ weeks & & $5(3.8)$ & & $99(6.0)$ \\
\hline & 3-4 weeks & & $6(4.5)$ & & $55(3.3)$ \\
\hline & 5-8 weeks & & $1(0.8)$ & & $33(2.0)$ \\
\hline & $>8$ weeks & & $3(2.3)$ & & $57(3.4)$ \\
\hline Time between head injury and triage & Hours & 131 & $6.8(9.4)$ & 1,665 & $9.5(12.1)$ \\
\hline Lost consciousness duration & Minutes & 132 & $0.1(0.5)$ & 1,662 & $0.1(0.7)$ \\
\hline Personal history of migraines & Yes & 131 & $18(13.7)$ & 1,663 & $243(14.1)$ \\
\hline Family history of migraine & Yes & 128 & $69(53.9)$ & 1,638 & 807 (49.3) \\
\hline Prior diagnosis of learning disability & Yes & 132 & $8(6.1)$ & 1,665 & $134(8.0)$ \\
\hline Prior diagnosis of attention deficit disorder & Yes & 131 & $8(6.1)$ & 1,662 & $156(9.4)$ \\
\hline Prior diagnosis of anxiety & Yes & 132 & $10(7.6)$ & 1,668 & $148(8.9)$ \\
\hline Prior diagnosis of depression & Yes & 131 & $2(1.5)$ & 1,670 & $61(3.7)$ \\
\hline Prior diagnosis of sleep disorder & Yes & 132 & $0(0.0)$ & 1,665 & $41(2.5)$ \\
\hline Seizure at time of injury & Yes & 131 & $4(3.1)$ & 1,666 & $28(1.7)$ \\
\hline Mechanism of injury & Sports/recreational play & 132 & $72(54.5)$ & 1,672 & $1172(70.1)$ \\
\hline PCSI-P headache & $0-6(6=$ severe $)$ & 131 & $4.1(1.8)$ & 1,571 & $3.7(1.8)$ \\
\hline PCSI-P nausea & $0-6$ (6= severe) & 131 & $4.9(1.5)$ & 1,571 & $3.2(2.0)$ \\
\hline PCSI-P balance & $0-6(6=$ severe $)$ & 131 & $2.1(2.0)$ & 1,570 & $1.7(2.0)$ \\
\hline PCSI-P dizziness & $0-6(6=$ severe $)$ & 131 & $3.3(2.1)$ & 1,570 & $2.8(2.0)$ \\
\hline PCSI-P sleep more & $0-6(6=$ severe $)$ & 131 & $2.9(2.6)$ & 1,571 & $1.5(2.2)$ \\
\hline PCSI-P feeling drowsy & $0-6$ (6= severe) & 131 & $4.2(1.8)$ & 1,571 & $3.1(2.1)$ \\
\hline PCSI-P sensitivity to light & $0-6(6=$ severe $)$ & 131 & $2.3(2.3)$ & 1,570 & $1.7(2.1)$ \\
\hline PCSI-P sensitivity to noise & $0-6(6=$ severe $)$ & 131 & $1.9(2.2)$ & 1,571 & $1.5(2.0)$ \\
\hline PCSI-P irritable & $0-6(6=$ severe $)$ & 131 & $1.4(2.1)$ & 1,571 & $0.9(1.6)$ \\
\hline PCSI-P feeling sad & $0-6(6=$ severe $)$ & 131 & $2.0(2.2)$ & 1,570 & $1.3(1.9)$ \\
\hline PCSI-P feeling nervous & $0-6(6=$ severe $)$ & 131 & $1.2(1.7)$ & 1,569 & $0.8(1.5)$ \\
\hline PCSI-P feeling emotional & $0-6(6=$ severe $)$ & 130 & $1.9(2.1)$ & 1,570 & $1.3(1.8)$ \\
\hline PCSI-P mental fog & $0-6(6=$ severe $)$ & 131 & $2.8(2.1)$ & 1,569 & $1.9(2.0)$ \\
\hline PCSI-P difficulty concentrating & $0-6(6=$ severe $)$ & 131 & $1.8(2.1)$ & 1,570 & $1.3(1.8)$ \\
\hline PCSI-P difficulty remembering & $0-6(6=$ severe $)$ & 130 & $1.5(2.0)$ & 1,571 & $1.0(1.7)$ \\
\hline PCSI-P vision problems & $0-6(6=$ severe $)$ & 131 & $1.4(2.0)$ & 1,570 & $1.3(1.9)$ \\
\hline PCSI-P feeling fatigue & $0-6(6=$ severe $)$ & 131 & $3.9(2.0)$ & 1,571 & $3.0(2.1)$ \\
\hline PCSI-P feeling confused & $0-6(6=$ severe $)$ & 131 & $1.4(2.0)$ & 1,570 & $0.8(1.5)$ \\
\hline PCSI-P feeling clumsy & $0-6(6=$ severe $)$ & 131 & $1.3(1.8)$ & 1,571 & $0.9(1.6)$ \\
\hline PCSI-P answers more slowly & $0-6(6=$ severe $)$ & 131 & $2.4(2.1)$ & 1,569 & $1.6(1.9)$ \\
\hline SAC normalized total score & & 132 & $-0.9(2.1)$ & 1,652 & $-0.4(1.6)$ \\
\hline BESS tandem stance \# of errors & $\begin{array}{l}\text { 0-10 (10 includes physically } \\
\text { unable to do test) }\end{array}$ & 129 & $6.3(3.8)$ & 1,645 & $4.2(3.8)$ \\
\hline
\end{tabular}

regressions were fitted separately for each of the imputed data sets, where parameter estimates are then averaged across these data sets, and imputationadjusted variance estimates are computed. Lastly, clustered standard errors for the treatment effect were estimated to account for potential intra-site correlation. All analyses were performed using $R$ version 3.3 .2 (rms, Hmisc packages). 


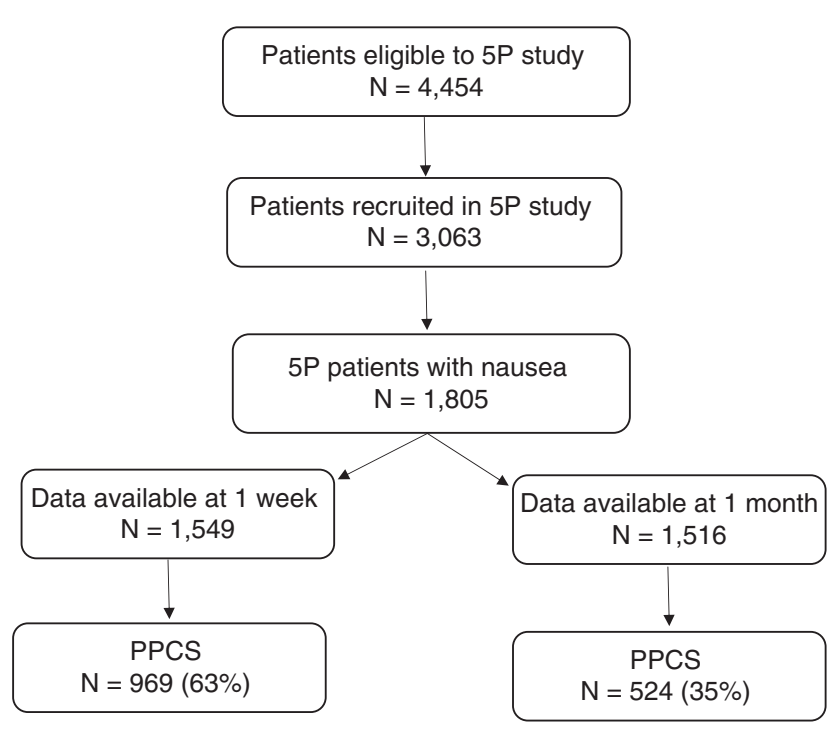

Figure 1. Flow diagram of participant recruitment and selection.

\section{RESULTS}

Among the 3,063 children included in the 5P study, 1,805 children were eligible for the current study (Figure 1), the PPCS outcome at week 1 was available for 1,549 children, and it was available for 1,516 children at 4 weeks. Table 1 demonstrates that baseline characteristics of the participants were similar between the two groups with the exception that patients in the ondansetron group received other medications more frequently than controls. Among these participants, 132 (7\%) received oral (120) or intravenous (10) ondansetron (2 received it by both routes). PPCS were present in $969 / 1,549(63 \%)$ at 1 week and 524/1,516 (35\%) at 1 month. With respect to the presence of nausea, $480 / 1,546(31 \%)$ reported this symptom at week 1 , and $212 / 1,518(14 \%)$ at week 4.

In the unadjusted analysis, the use of ondansetron was not statistically associated to the PPCS at 1 week (OR: 1.08 [95\% CI: 0.73-1.59]) or 1 month (OR: 1.18 [95\% CI: 0.80-1.74]) (Table 2). Once adjusted for covariates, there remained no statistical association between ondansetron use and the risk of PPCS at 1 week (adjusted OR: 1.17 [95\% CI: 0.68-2.04]); however, an increase association was observed at 1 month (OR: 1.33 [95\% CI: 1.05-1.68]).

Use of ondansetron in the ED was not statistically associated to the presence of nausea at 1 week or 1 month following the ED visit on univariate logistic regression and after adjusting for other predictors (see Table 2).

\section{DISCUSSION}

This study failed to identify a decrease in post-concussion symptoms at 1 week and 1 month following a concussion among children ages 5 to 17.99 years who received ondansetron in the ED. However, the use of ondansetron was associated with an increase in the risk of PPCS at 1 month on multiple regression.

There is a paucity of literature specifically describing the use of ondansetron for patients with head trauma and, to our knowledge, no study has evaluated other antiemetics for long-term concussion symptoms. A retrospective cohort study involving 6,311 children with head concussion reported a lower risk of revisit associated with the use of ondansetron in children. ${ }^{25}$ However, major differences between the two study populations (use of ondansetron, $25 \%$ v. $7 \%$ ), the proportion of a computed tomography (CT) scan (100\% v. $4 \%$ ) and the number of sites involved may have led to confounding by severity the sicker patients being more at risk of receiving ondansetron and having PPCS. Another small pilot study conducted to assess the feasibility of a randomized controlled trial of the impact of ondansetron in concussed teenagers ${ }^{26}$ reported a trend towards a lower proportion of children with PPCS at 1 week (OR: 0.60 [95\% CI: 0.08-4.4]) and 1 month (OR: 0.20 [95\% CI: 0.02-1.70]) following oral ondansetron. ${ }^{27}$

From a theoretical perspective, ondansetron holds promise for potentially minimizing post-concussion symptoms. The most commonly cited hypothesis for the pathophysiology of concussion suggests that shear forces experienced at the time of injury lead to ionic fluxes, the releases of excitatory neurotransmitters, and a spreading depression-like phenomenon. ${ }^{28-32}$ The decreased cerebral blood flow after injury ${ }^{31}$ limits the influx of adenosine triphosphate (ATP) required to restore homeostasis. The mismatch between demand and supply for ATP may prolong concussion symptoms. As such, physical and cognitive rest may improve recovery through conservation of limited ATP supplies following injury to the brain. Ondansetron may improve recovery from concussion by decreasing early symptoms of nausea and vomiting, which has been associated with PPCS at 3 months. ${ }^{33}$ Also, this could improve rest and improve recovery because it was previously demonstrated that PPCS is inversely related 
Table 2. Association between use of ondansetron and outcomes $(n=1,805)$

\begin{tabular}{lcccc}
\hline Outcome & Outcome in ondansetron* $(n=132)$ & Outcome in control* $^{*}(\mathrm{n}=1,673)$ & Unadjusted OR (95\% Cl) Adjusted OR (95\% Cl) \\
\hline PCS at 1 week (\%) & $77 / 120(64.2)$ & $892 / 1,429(62.4)$ & $1.08(0.79-1.47)$ & $1.17(0.68-2.04)$ \\
PCS at 1 month (\%) & $45 / 118(38.1)$ & $479 / 1,398(34.3)$ & $1.18(0.91-1.54)$ & $1.33(1.05-1.68)$ \\
Nausea at 1 week & $34 / 118(28.8)$ & $446 / 1,428(31.2)$ & $0.89(0.60-1.32)$ & $0.76(0.42-1.38)$ \\
Nausea at 1 month & $16 / 119(13.4)$ & $196 / 1,399(14.0)$ & $0.95(0.54-1.69)$ & $0.88(0.47-1.64)$
\end{tabular}

*The denominator changes depending on how many missing values on the outcome (due to loss to follow-up or participant simply not completing question); values reflect raw data prior to performing multiple imputations.

${ }^{\dagger}$ To prevent from overfitting, the number of model covariables included depended on sample size considerations (i.e., number of observations in a smaller level of binary study outcome). See Table 1 for specific covariables included in each model.

to rest quality. ${ }^{34,35}$ On the other hand, ondansetron could also be deleterious to recovery for multiple reasons. By minimizing the initial symptoms, it could hasten return to play and limit brain rehabilitation, as well as increase the risk of a second impact on brain cells. However, a recent study showed that early activity was associated with a lower risk of PPCS. ${ }^{36}$ Also, decreasing initial symptoms could modify medication consumption or feeding. Finally, ondansetron's effect on 5HT-3 receptors may interplay with an energy homeostasis of the brain and slow recovery process.

The clinical impact of this study is limited by its exploratory design. However, it raises the question as to whether ondansetron may have a deleterious effect on brain recovery following concussion. Consequently, the treatment of short-term symptoms like nausea and vomiting should be balanced with the potential longterm harm of ondansetron.

There are several limitations inherent to the current study. Among them, the use of an observational design is prone to bias by indication. It is possible that the baseline risk of PPCS was different for children who received ondansetron than for the control group. They may have suffered from a more severe concussion. To account for this, we adjusted the analysis according to multiple factors identified in the 5P study. To balance for unknown risk factor, it would be important to conduct a randomized clinical trial. Missing data limited the precision of our findings. To account for this, we used multiple imputation techniques. Although this permitted to include more patients, there is a risk of unknown biases related to missing data. Another limitation is the absence of a standard dose, number, or route of administration of the ondansetron. This may impact effectiveness of the medication and could be addressed by another study. Also, we did not collect information regarding home medication. Finally, the inclusion of patients who received other antiemetic medication in the control group may have biased the result towards the null hypothesis. However, there were very few patients for whom other antiemetic medication administration was documented.

In conclusion, this exploratory sub-analysis failed to identify a decrease in the risk of PPCS at 1 week among children ages 5 to 17.99 years who suffered a concussion and received ondansetron in the ED. Moreover, as a group, patients who received ondansetron had a worse outcome at 1 month. While this may be related to the design of our study, it highlights the importance of evaluating the impact of this medication on recovery from concussion. Future studies should continue to explore potential therapies to mitigate ongoing concussion symptoms and sequelae.

Competing interests: None declared.

\section{SUPPLEMENTARY MATERIALS}

To view supplementary material for this article, please visit https://doi.org/10.1017/cem.2018.384

\section{REFERENCES}

1. Amoo-Achampong K, Rosas S, Schmoke N, et al. Trends in sports-related concussion diagnoses in the USA: a population-based analysis using a private-payor database. Phys Sportsmed 2017;45(3):239-44.

2. Zhang AL, Sing DC, Rugg CM, et al. The rise of concussions in the adolescent population. Orthop 7 Sports Med 2016;4(8). doi:10.177/2325967116662458.

3. Carroll LJ, Cassidy JD, Peloso PM, et al. Prognosis for mild traumatic brain injury: results of the WHO Collaborating Centre Task Force on Mild Traumatic Brain Injury. F Rebabil Med 2004;(43 Suppl):84-105.

4. Pertab JL, James KM, Bigler ED. Limitations of mild traumatic brain injury meta-analyses. Brain Inj 2009;23 (6):498-508.

5. Zemek R, Barrowman N, Freedman SB, et al. Clinical risk score for persistent postconcussion symptoms among 
children with acute concussion in the ED. FAMA 2016;315 (10):1014-25.

6. Ingebrigtsen $\mathrm{T}$, Waterloo $\mathrm{K}$, Marup-Jensen $\mathrm{S}$, et al. Quantification of post-concussion symptoms 3 months after minor head injury in 100 consecutive patients. 7 Neurol 1998;245(9):609-12.

7. Alexander MP. Mild traumatic brain injury: pathophysiology, natural history, and clinical management. Neurology $1995 ; 45(7): 1253-60$.

8. Reitan RM, Wolfson D. The two faces of mild head injury. Arch Clin Neuropsychol 1999;14(2):191-202.

9. Zemek RL, Grool AM, Rodriguez Duque D, et al. Annual and seasonal trends in ambulatory visits for pediatric concussion in Ontario between 2003 and 2013. F Pediatr 2017;181:222-8.e2.

10. McCrory P, Meeuwisse WH, Aubry M, et al. Consensus statement on concussion in sport: the 4th International Conference on Concussion in Sport held in Zurich, November 2012. Br 7 Sports Med 2013;47(5):250-8.

11. Marshall S, Bayley M, McCullagh S, et al. Clinical practice guidelines for mild traumatic brain injury and persistent symptoms. Can Fam Physician 2012;58(3):257-40.

12. Harmon KG, Drezner JA, Gammons M, et al. American Medical Society for Sports Medicine position statement concussion in sport. Br 7 Sports Med 2013;47(1):15-26.

13. Herring SA, Cantu RC, Guskiewicz KM, et al. Concussion (mild traumatic brain injury) and the team physician: a consensus statement - 2011 update. Med Sci Sports Exerc 2011;43(12):2412-22.

14. Giza CC, Kutcher JS, Ashwal S, et al. Summary of evidencebased guideline update: evaluation and management of concussion in sports: report of the Guideline Development Subcommittee of the American Academy of Neurology. Neurology 2013;80(24):2250-7.

15. Borg J, Holm L, Peloso PM, et al. Non-surgical intervention and cost for mild traumatic brain injury: results of the WHO Collaborating Centre Task Force on Mild Traumatic Brain Injury. 7 Rehabil Med 2004;(43 Suppl):76-83.

16. Comper P, Bisschop SM, Carnide N, Tricco A. A systematic review of treatments for mild traumatic brain injury. Brain Inj 2005;19(11):863-80.

17. Gravel J, D'Angelo A, Carriere B, et al. Interventions provided in the acute phase for mild traumatic brain injury: a systematic review. Syst Rev 2013;2:63.

18. King D, Brughelli M, Hume P, Gissane C. Assessment, management, and knowledge of sport-related concussion: systematic review. Sports Med 2014;44(4):449-71.

19. Sturm JJ, Pierzchala A, Simon HK, Hirsh DA. Ondansetron use in the pediatric emergency room for diagnoses other than acute gastroenteritis. Pediatr Emerg Care 2012;28 (3):247-50.

20. Freedman SB, Uleryk E, Rumantir M, Finkelstein Y. Ondansetron and the risk of cardiac arrhythmias: a systematic review and postmarketing analysis. Ann Emerg Med 2014;64(1):19-25.e6.

21. Sady MD, Vaughan CG, Gioia GA. Psychometric characteristics of the postconcussion symptom inventory in children and adolescents. Arch Clin Neuropsychol 2014;29(4):348-63.

22. King NS. Emotional, neuropsychological, and organic factors: their use in the prediction of persisting postconcussion symptoms after moderate and mild head injuries. 7 Neurol Neurosurg Psychiatry 1996;61(1):75-81.

23. King NS, Crawford S, Wenden FJ, et al. Early prediction of persisting post-concussion symptoms following mild and moderate head injuries. Br 7 Clin Psychol 1999;38(Pt 1):15-25.

24. White IR, Royston P, Wood AM. Multiple imputation using chained equations: issues and guidance for practice. Stat Med 2011;30(4):377-99.

25. Sturm JJ, Simon HK, Khan NS, Hirsh DA. The use of ondansetron for nausea and vomiting after head injury and its effect on return rates from the pediatric ED. Am 7 Emerg Med 2013;31(1):166-72.

26. Gravel J, Carriere B, D'Angelo A, et al. Ondansetron for pediatric concussion; a pilot study for a randomized controlled trial. C7EM 2017;19(5):338-46.

27. Gravel J, Carriere B, D'Angelo A, et al. Ondansetron for pediatric concussion; a pilot study for a randomized controlled trial. C7EM 2017;19(5):338-46.

28. Giza CC, Hovda DA. The neurometabolic cascade of concussion. 7 Athl Train 2001;36(3):228-35.

29. Yoshino A, Hovda DA, Kawamata T, et al. Dynamic changes in local cerebral glucose utilization following cerebral conclusion in rats: evidence of a hyper- and subsequent hypometabolic state. Brain Res 1991;561(1):106-19.

30. Shaw NA. The neurophysiology of concussion. Prog Neurobiol 2002;67(4):281-344.

31. Maugans TA, Farley C, Altaye M, et al. Pediatric sportsrelated concussion produces cerebral blood flow alterations. Pediatrics 2012;129(1):28-37.

32. Shrey DW, Griesbach GS, Giza CC. The pathophysiology of concussions in youth. Phys Med Rebabil Clin $N$ Am 2011;22(4):577-602; vii.

33. Babcock L, Byczkowski T, Wade SL, et al. Predicting postconcussion syndrome after mild traumatic brain injury in children and adolescents who present to the emergency department. 7AMA Pediatr 2013;167(2):156-61.

34. Boutis K, Cogollo W, Fischer J, et al. Parental knowledge of potential cancer risks from exposure to computed tomography. Pediatrics 2013;132(2):305-11.

35. Moser RS, Glatts C, Schatz P. Efficacy of immediate and delayed cognitive and physical rest for treatment of sportsrelated concussion. 7 Pediatr 2012;161(5):922-6.

36. Grool AM, Aglipay M, Momoli F, et al. Association between early participation in physical activity following acute concussion and persistent postconcussive symptoms in children and adolescents. FAMA 2016;316(23):2504-14. 